\title{
Modelling customer choice and market development for future automotive powertrain technologies
}

\author{
Martin Redelbach ${ }^{1}$, Michael Sparka ${ }^{1}$, Stephan Schmid ${ }^{1}$, Horst E. Friedrich ${ }^{1}$ \\ ${ }^{1}$ Institute of Vehicle Concepts, German Aerospace Center (DLR), Stuttgart, Germany, Martin.Redelbach@dlr.de
}

\begin{abstract}
The paper introduces an innovative utility-based approach to model customer choice for alternative powertrain technologies within a dynamic scenario tool. The study covers a wide portfolio of different powertrain concepts from conventional combustion engines to advanced hybrid and electric cars. The assessment of their economic and technical attributes builds on a large set of vehicle simulation data and detailed cost models. In contrast to previous cost-based studies the applied methodology maps the observed diversity of user characteristics more realistically. Therefore, the driving behaviour and preferences of car buyers are analysed empirically based on major representative surveys and the resulting distribution functions are integrated in the model. After testing and validation with historic data the model is applied to the German vehicle market and a potential scenario for the prospective composition of the new passenger car fleet by 2030 is presented. The scenario simulation shows that a significant reduction of $\mathrm{CO}_{2}$ emissions is feasible especially by the introduction of plug-in hybrids and range extended electric vehicles. However, the growing technical complexity and the additional effort for efficiency improvements also result in increasing total costs of ownership for the customer.
\end{abstract}

Keywords: Market potential, TCO, purchase and user behavior, hybrid and battery electric vehicles

\section{Introduction}

In the context of increasing climate protection efforts, limited fossil resources and rising environmental awareness from customer side the electrification of the powertrain is a preeminent development in the transport sector. The European Commission's transport strategy aims to cut greenhouse gas emissions by at least $60 \%$ until 2050 [1]. The German government plans to reduce the energy consumption of transport by $40 \%$ in 2050 (compared to 2005 level) according to the recently published mobility and fuel strategy [2]. Reaching these goals will not be feasible with conventional combustion engines. Therefore a variety of propulsion concepts from mild hybrids to full electric cars are currently developed and will be introduced into the market by all mayor OEMs over the next years. However, the question which technology will be accepted by the user and hence will prevail in the long run has not been answered yet.

As a consequence of this development the decision process for car buyers is becoming more and more complex. While in the past a user could basically choose between spark ignition (SI) and compression ignition (CI) engines, which have only minor differences in purchase price and fuel consumption, the powertrain portfolio offered by 
the automotive industry will grow in the future. At the same time the attributes of these advanced drivetrain architectures vary significantly. Investment and operating costs of the vehicle are definitely important for the user. However, minimizing cost is not sufficient to fully understand the future purchase behaviour of car buyers. Additional vehicle attributes, e.g. $\mathrm{CO}_{2}$ emissions, driving range, and driving performance, as well as the individual willingness to pay have to be taken into account [3]. Therefore, this paper presents an innovative approach how to choose the optimal powertrain technology for different user characteristics and preferences within a dynamic market scenario model.

\section{Methodology}

Previous studies on the future penetration of alternative drivetrain concepts can be grouped into two major fields. The first one focuses on the technological potential and the projected cost development of the new propulsion systems. Here total cost of ownership (TCO) is widely used as key indicator to evaluate the competitiveness of electric vehicles. Important contributions in this research field have been made among others by Lipman [4], Delucci [5],
Kromer [6], Van Vliet [7] and Santini [8]. The second group applies advanced statistical methods, especially discrete choice models (e.g. Berry [9], Train [10], Golob [11] and Ziegler [12]) to assess the purchase behaviour of today's consumers. Based on their observations the researchers try to derive predictions on the future success of EVs. While the cost centered approach is criticized for assuming an unrealistic homo economicus and neglecting other important vehicle attributes and the importance of consumer preferences [13], econometric studies traditionally put only a low emphasis on the technological side. Furthermore, discrete choice analyses are usually static, i.e. the vehicle properties and costs are provided externally which does not allow to model dynamic market scenarios over a long period of time.

The paper introduces a new interdisciplinary approach to model customer choice behaviour for conventional and advanced powertrain technologies by combining vehicle simulations, scenario technique and discrete choice analyses in a dynamic utility based market model. Figure 1 provides an overview on the model structure, which consists of the following modules:

- Vehicles: A wide set of different drivetrain architectures is covered by the model including vehicles with internal combustion engine

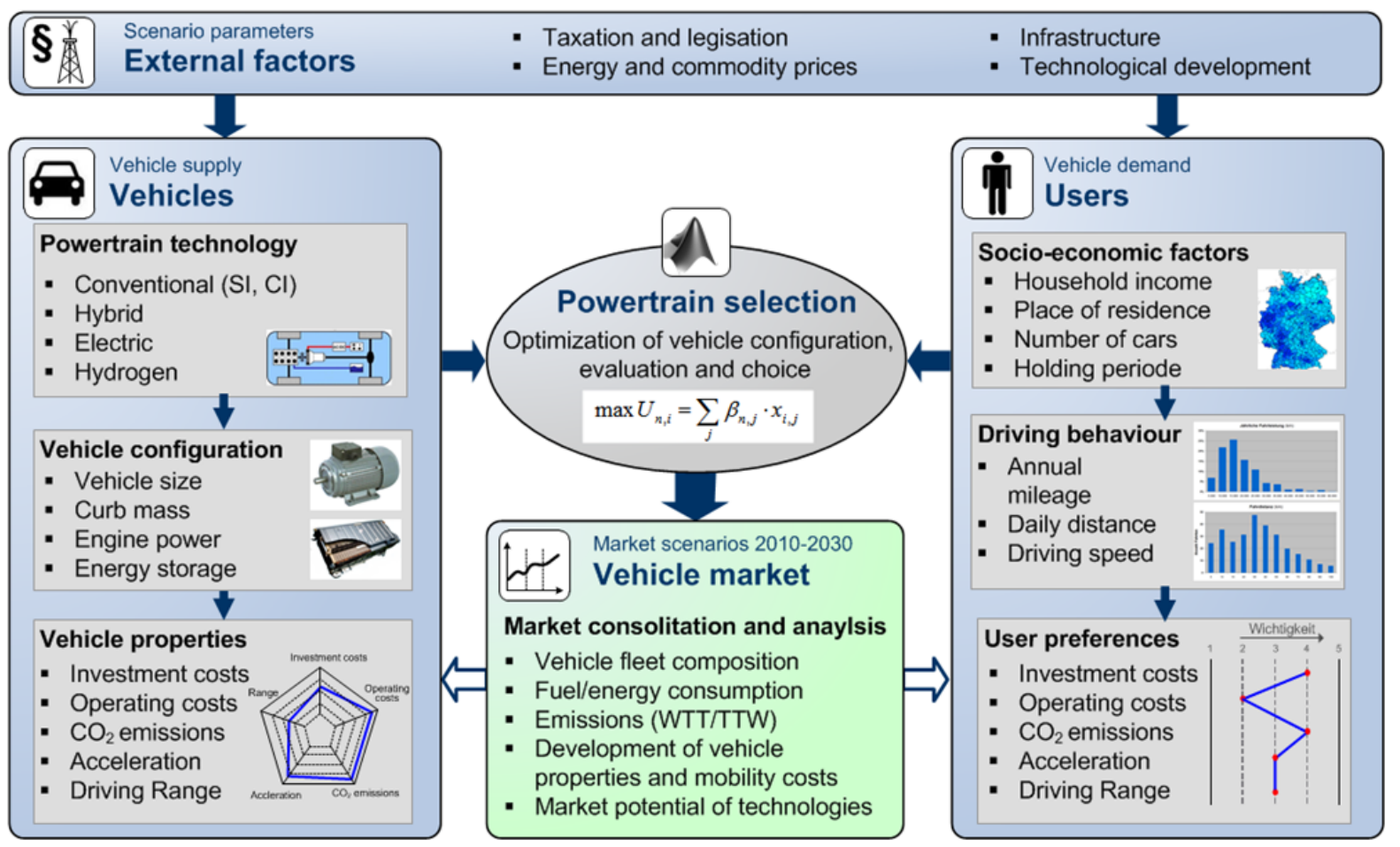

Figure 1: Structure of the market model 
powered by gasoline, diesel or compressed natural gas (CNG), hybrids (HEV), plug-in hybrids (PHEVs), extended range electric vehicles (EREVs), battery electric vehicles (BEVs) and fuel cell electric vehicles (FCEVs). The car configuration is flexible in several dimensions, e.g. curb mass, motor power or energy storage size. According to the selected setup key vehicle characteristics like costs, energy consumption and performance are calculated dynamically by the model [14].

- User: The model maps the diversity of car buyers in terms of socioeconomic factors, driving behaviour and individual preferences by applying a stochastic distribution functions. The underlying empirical data is based on the analysis of large representative surveys covering more than 30,000 respondents in Germany, e.g. the national travel survey Mobility in Germany (MiD) [15] and the consumer survey Verbraucheranalyse [16].

- External factors: A large set of scenario parameters which influence the purchase decision is included in the model (e.g. energy prices, $\mathrm{CO}_{2}$ regulations, incentives and technology learning curves). These factors defined externally enable the model operator to simulate different market scenarios and to assess the impact of selected policy measures.

- Vehicle market: The results of the individual purchase decision are consolidated in market module which scales up the simulation results to be representative for the German car fleet. It also facilitates analysing the macroeconomic impact on $\mathrm{CO}_{2}$ emissions, fuel consumption or mobility costs for the consumer. Moreover, the simulated market data can be used to identify early adaptor groups for electric vehicles by analysing which user types prefer which powertrain technology.

The center of this agent based model is the powertrain selection algorithm which is formulated as a utility maximization problem. While other vehicle market models such as presented by Mock [17], Kihm [18] or Plötz [19] apply TCO minimization as the objective of the customer, the introduction of utility as scoring variable allows multi-criteria decision making by the car buyer. The model provides the possibility to implement different decision functions. In this study a linear utility function is applied where $U$ represents the relative value a user $n$ assigns to a powertrain option $p$ :

$$
\max U_{n, p}=\sum_{i} \beta_{n, i} \cdot x_{p, i}+\varepsilon
$$

The utility score is determined by the vehicle attributes $x$ (depending on the powertrain technology $p$ ) and the individual preferences $\beta$ (depending on the characteristics of user $n$ ). In the current model version the following criteria $i$ are evaluated: purchase price, operating cost (incl. fuel, electricity, maintenance and repair), $\mathrm{CO}_{2}$ emissions, acceleration performance and driving range. In an iterative process each customer first adjusts the car configuration according to his preferences and then chooses the option with the highest score $U$. The iteration of this decision process for a large set of $N$ users per year over a given time period allows analysing the future market prospects of alternative propulsion technologies.

\section{Model data}

In this study the model is applied to the German car market to assess the competitiveness and environmental impact of different powertrain concepts in the time horizon 2010-2030. Therefore an extensive data set is required as model input. The following paragraphs provide a brief overview on the data sources for vehicle, user and scenario data applied in the market simulation.

\subsection{Vehicle data}

To determine the energy consumption and driving performance of the selected powertrains the DLR proprietary Modelica library AlternativeVehicles [20] is applied and the simulation results are integrated into the model. The model covers eight different drivetrain architectures from conventional internal combustion engines (ICE SI/CI) to advanced technologies like battery electric vehicles in three car segments. In a first step the basic vehicle parameters (like curb weight, retail price, fuel consumption etc.) are calibrated to represent average passenger cars in small, medium and large segment sold in the Germany 2010 (according to ADAC [21] and KBA [22] data). The gasoline ICE, which dominated the car market in the past, serves as reference vehicle. All other powertrains are configured to show comparable performance characteristics (e.g. acceleration 0$100 \mathrm{~km} / \mathrm{h}$ in $9-10 \mathrm{~s}$ in the medium segment). To 
get realistic fuel economy data for the subsequent cost analysis, the assumed average power consumption of auxiliaries has been included in the simulation $(0.7-2.0 \mathrm{~kW})$. While HEV and PHEV use a parallel hybrid powertrain, the EREV is designed as series hybrid with larger battery. The size of the traction battery is dimensioned to reach an all-electric range of more than $50 \mathrm{~km}$ for the EREV and more than $100 \mathrm{~km}$ for the BEV. The PHEV is able to drive $35 \mathrm{~km}$ in all-electric mode in the urban part of the NEDC with a maximum velocity of $50 \mathrm{~km} / \mathrm{h}$. The HEV battery is sufficient to store the entire recuperation energy during the cycle. A summary of the most relevant underlying vehicle parameters for the midsize segment is presented in Table 1.

The cost development of the electric vehicle concepts over time is projected by a detailed TCO model. The calculation covers all types of expenses arising for a vehicle owner over lifetime including acquisition cost, operating cost, vehicle tax as well as maintenance and repair and the expected resale value. For the core components of the electric drivetrain (traction battery, electric machine and power electronics) specialized models, which have been developed at the DLR Institute of Vehicle Concepts, are applied to projects the future cost development. These models use a learning curve approach to forecast the cost degression dynamically with increasing economies of scale [23]. For example, the battery cost model estimates the cell, module, and pack production cost for the most important Li-ion chemistries as a function of the production volume [24]. In this assessment NMC has been selected for high-energy storage with a learning rate of $86 \%$ (i.e. with a doubling of output the average production cost decrease by $14 \%$ due to economies of scales). For more details on the TCO calculation see [25], [26].

\subsection{User data}

For the modelling of the car user characteristics several empirical surveys and data sources have been analysed and integrated into the market model. Reflecting the diversity of consumers the population is segmented in three groups along the following three dimensions: annual mileage, household income and place of residence (see Figure 2).

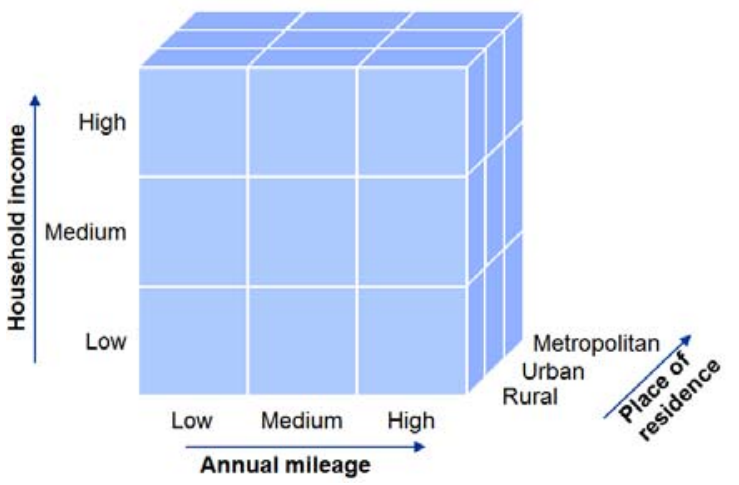

Figure 2: Dimensions of user segmentation

For each of the resulting 27 customer segments the distribution of preferences when buying a new car has been evaluated based on the data of a large representative consumer survey in Germany [16]. In this survey the respondents have been asked to rate the importance of multiple vehicle attributes when buying a new car. An excerpt of this analysis in Figure 3 contrasts the relative importance for purchase price, $\mathrm{CO}_{2}$ emissions and acceleration performance of a single user segment (in this case frequent drivers with high income living in a rural area) against the average distribution.

Table 1: Vehicle parameter (midsize segment)

\begin{tabular}{|c|c|c|c|c|c|c|c|c|c|c|}
\hline & Parameter & Unit & ICE-SI & ICE-CI & HEV & PHEV & EREV & BEV & FCEV & CNG \\
\hline \multirow{3}{*}{$\begin{array}{c}\text { Energy } \\
\text { converter }\end{array}$} & Combustion engine & $k W$ & 100 & 100 & 100 & 100 & 50 & - & - & 100 \\
\hline & Electric drive & $k W$ & - & - & 25 & 25 & 100 & 100 & 100 & - \\
\hline & Fuel cell stack & $k W$ & - & - & - & - & - & - & 100 & - \\
\hline \multirow{3}{*}{$\begin{array}{l}\text { Energy } \\
\text { storage }\end{array}$} & Battery & $k W h$ & - & - & 2 & 7.5 & 15 & 30 & 2.5 & - \\
\hline & $\mathrm{H}_{2} / \mathrm{CNG}$ tank & $\mathrm{kg}$ & - & - & - & - & - & - & 4 & 25 \\
\hline & Fuel tank & $l$ & 50 & 50 & 50 & 40 & 30 & - & - & - \\
\hline \multirow{4}{*}{$\begin{array}{c}\text { Driving } \\
\text { resistance }\end{array}$} & Curb mass & $\mathrm{kg}$ & 1400 & 1470 & 1510 & 1570 & 1610 & 1610 & 1790 & 1540 \\
\hline & Frontal area & $m^{2}$ & \multicolumn{8}{|c|}{2.2} \\
\hline & Aerodynamic drag & & \multicolumn{8}{|c|}{0.28} \\
\hline & Rolling resistance & & \multicolumn{8}{|c|}{0.1} \\
\hline
\end{tabular}




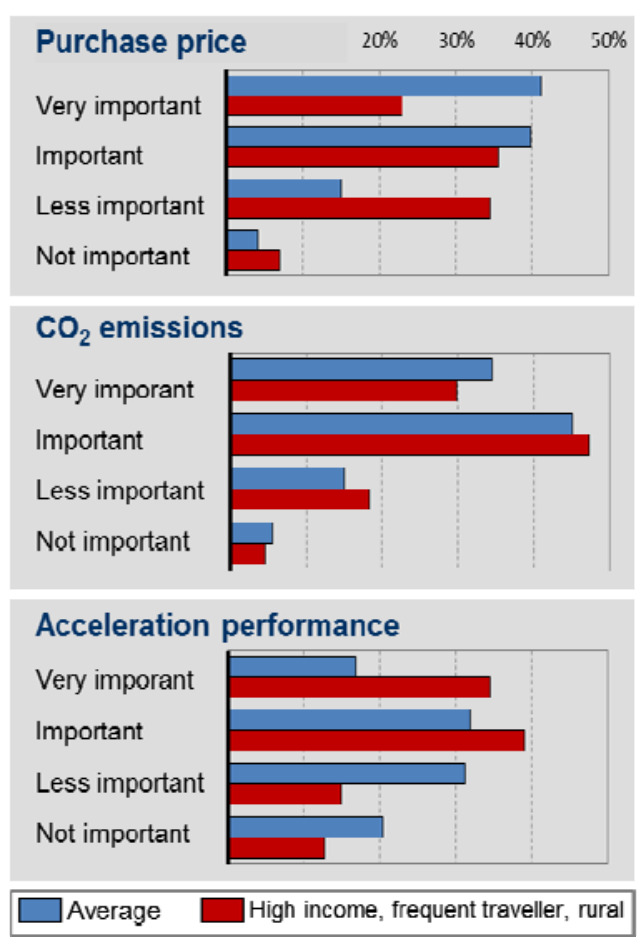

Figure 3: Distribution of customer preferences regarding selected vehicle criteria (own analysis based on [16])

The results indicate that the selected group with high purchase power values driving performance significantly higher than the population average, while the importance of the car price is relatively low. In line with this example the survey data has been used to model the preference distribution across all user segments. Furthermore, the average willingness to pay has been calibrated by performing a meta-analysis of available discrete choice analyses [27].

Besides individual attitudes and preferences the decision of a car buyer is also influenced by his driving behaviour. As electrified powertrains usually have higher initial investment costs, but lower running costs over life time, the economics of different technologies are strongly affected by the annual mileage and holding period [26]. Both quantities are analysed for German car drivers based on the national travel survey MiD and are integrated as a statistical distribution in the model. The resulting distribution functions for the annual mileage of small, medium and large cars are described mathematically by a lognormal fit. The plot in Figure 4 demonstrates that holders of small cars drive on average significantly less $(11,600 \mathrm{~km} /$ year $)$ than holders of larger vehicles $(15,600 \mathrm{~km} /$ year $)$.

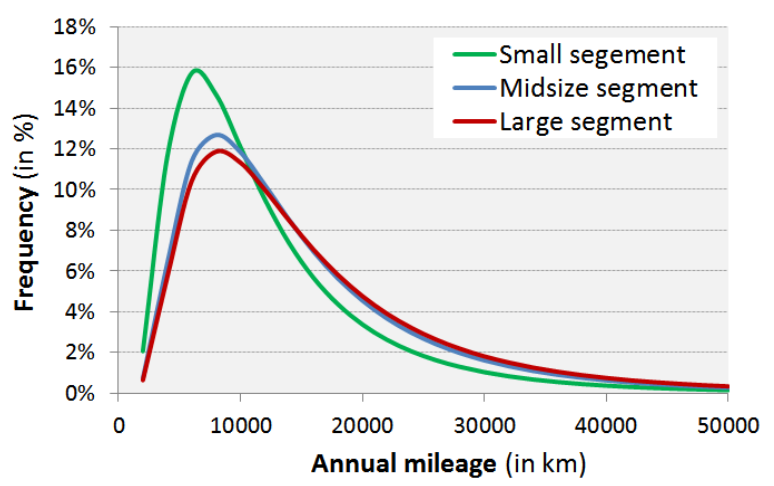

Figure 4: Distribution of annual mileage for different car segments in Germany (analysis based on [15])

Moreover, the MiD data is also applied to determine the average driving speed of different user types. The empirical data shows a functional relationship between mean speed and annual mileage. People who are used to travel longer distances spend more time on motorways with a higher average velocity than short distance drivers. Additionally, the driving speed is also influenced by the place of residence. City dwellers show a considerably lower average speed at short distances than inhabitants of rural areas due to frequent stop-and-go and traffic jams in metropolitan areas. With increasing driving distance the observed average speed converges between all groups (see Figure 5). To take these differences in driving style into account the mix of urban and extra-urban driving is adjusted in the model in a way so that the weighted average of the simulated driving cycle equals the statistically observed mean speed.

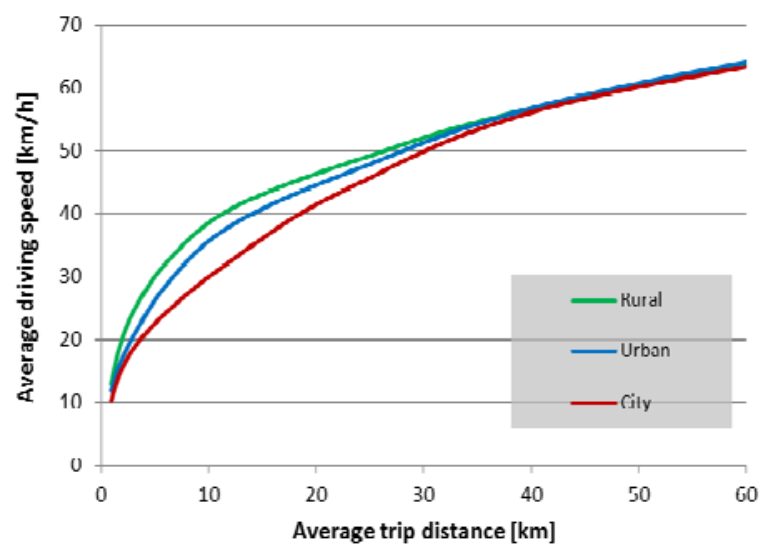

Figure 5: Average driving speed in Germany as a function of trip distance and place of residence [28] 
Table 2: Summary of scenario parameters (in real prices year 2010)

\begin{tabular}{|c|c|c|c|c|c|c|c|c|}
\hline & Parameter & Unit & 2010 & 2015 & 2020 & 2025 & 2030 & Source \\
\hline \multirow{3}{*}{$\begin{array}{l}\text { Energy } \\
\text { prices }\end{array}$} & Oil price & $U S D / b b l$ & 80 & 106 & 118 & 127 & 135 & IEA [29] \\
\hline & Electricity price & $E U R / \mathrm{kWh}$ & 0.25 & 0.26 & 0.27 & 0.26 & 0.26 & BMU [30] \\
\hline & Hydrogen price & $E U R / \mathrm{kg}$ & 16.6 & 9.9 & 6.6 & 5.5 & 5.0 & EU Coalation Study \\
\hline \multirow{3}{*}{$\begin{array}{c}\mathrm{CO}_{2} \\
\text { regulation }\end{array}$} & $\mathrm{CO}_{2}$ fleet limit & $\mathrm{g} / \mathrm{km}$ & - & 130 & 95 & 82,5 & 70 & EU regulation (interpolated) \\
\hline & $\mathrm{CO}_{2}$ penalties & $E U R /(\mathrm{g} / \mathrm{km})$ & 0 & 95 & 95 & 95 & 95 & EU regulation \\
\hline & Super credits & & 3,5 & 2,5 & 2 & 1 & 1 & EU parlament [31] \\
\hline \multirow{4}{*}{$\begin{array}{c}\text { Economic } \\
\text { parameter }\end{array}$} & Discount factor & $\%$ & \multicolumn{5}{|c|}{5} & \\
\hline & Car holding period & & \multicolumn{5}{|c|}{ Statistically dis tributed $1-10$ years } & Analysis based on [15] \\
\hline & Willingness to pay & & \multicolumn{5}{|c|}{$\begin{array}{l}\text { Distribution of preferences based on consumer analysis } \\
\text { (no positive image effect for single powertrains assumed) }\end{array}$} & $\begin{array}{l}\text { Meta-analysis discrete } \\
\text { choice models, [16] }\end{array}$ \\
\hline & Financial incentives & & \multicolumn{5}{|c|}{ No direct financial bonus for buyers of low emission vehicle } & Current German legislation \\
\hline
\end{tabular}

\subsection{Scenario data}

For the following simulation of the German car market a set of scenario assumptions have to be defined. The most relevant input parameters are summarized in Table 2. For exogenous factors such as energy prices a moderate business-asusual scenario is assumed based on several renowned sources. For instance the oil price development reflects the current policy scenario published in IEA World Energy Outlook [29], which projects an average growth rate of $2.6 \%$ p.a. from 2010 to 2030 . Electricity costs are based on expected end customer prices for Germany as specified in the 2012 study of the German Federal Environment Ministry [30]. The $\mathrm{CO}_{2}$ emission regulation of the European Union which limits the new car fleet emission to $95 \mathrm{~g} / \mathrm{km}$ in 2020 is extrapolated to $70 \mathrm{~g} / \mathrm{km}$ by 2030. In this context low emission vehicles below $50 \mathrm{~g} \mathrm{CO}_{2} / \mathrm{km}$ benefit from super credits which are faded out gradually until 2025 according to the latest EU proposal [31]. In contrast to other countries in Germany as of today no direct financial incentives are granted to the buyers of electric cars from government side apart from the exemption of motor vehicle tax for BEVs (with savings of EUR 50-100 per year). The composition of the passenger car market in Germany for the base year 2010 reflects the segment split according to KBA data. For the future market development a limited growth in sales figure and a slow shift towards smaller cars are assumed in line with market forecast from ÍHS Global Insight [32].

\section{Results and discussion}

The newly developed market simulation tool enables a great variety of different analyses based on the model output. In the following the scenario results for the future penetration of alternative powertrains are presented and the impact on $\mathrm{CO}_{2}$ emissions and cost for the user are discussed. Prior to this the model is tested with a historical case study.

\subsection{Model validation}

To validate the model and evaluate the capabilities of the novel utility based approach the historical market development in Germany is simulated and compared with real world data. Therefore all relevant input parameters, e.g. fuel prices and the energy consumption of the available vehicles are adjusted to reflect the situation in Germany in the years from 1993 to 2010 [33].

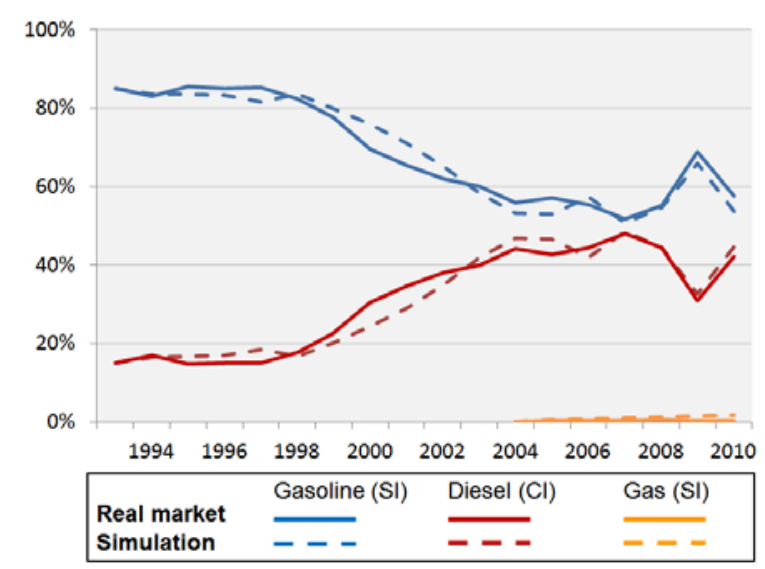

Figure 6: Market share of different powertrain technologies in Germany 1993-2010, historic development vs. market simulation [33]

The simulation results in Figure 6 demonstrate that the model predicts correctly the increasing market share of diesel cars from $15 \%$ to $44 \%$ during this time period. The average (absolute) deviation between the simulated and the real market share of the different powertrain technologies equals $3.5 \%$. If the stochastic term $\varepsilon$ in the linear utility function 
(1) is calibrated to reflect the limited availability of gas vehicles on the supply side and the observed consumer reluctance for this technology on demand side the mean deviation is reduced to $1.7 \%$. For comparison the simulation is repeated with a conventional least-TCO approach which results in a mean deviation of $5.8 \%$. This comparison underlines the benefit of the new utility-based model approach which makes it possible to integrate multiple criteria and realistic user characteristics into the decision logic.

\subsection{Vehicle market}

The simulation results for the new vehicle market in Germany are presented in Figure 7 differentiated by powertrain technology. Based on the scenario assumptions described in the previous chapter conventional ICE powered by gasoline and diesel are expected to dominate the market over next decade. The political target of 1 million electric cars until 2020 set by the German government is not reached in this scenario. However, beyond 2020 the share of hybrid electric vehicles is expected to grow strongly. According to the market simulation more than $50 \%$ of the new passenger cars in 2030 will be grid connected (PHEV, EREV, BEV). On the other hand $90 \%$ of the cars still have a combustion engine on board, which is powered by oil-based fuels. The number of $\mathrm{CNG}$ cars increases, but does not surpass a market share of more than $4 \%$. One reason for the limited growth expectations of $\mathrm{CNG}$ is the increasing energy price when the current tax advantage of natural gas as motor fuel ends in 2018, as assumed in this scenario. Another reason is the growing competition through hybrid electric cars which have even lower running cost and $\mathrm{CO}_{2}$ emissions. The number of full electric vehicles grows steady within the next two decades, but they continue to stay a niche product with an overall market share of $6 \%$. For most customers PHEV and EREV are more attractive options as they offer electric driving without the strict range limitation of BEVs. (The main disadvantage of BEVs in the utility rating according to formula (1) is caused by the low driving range. In most cases only users with more than one car who have lower range requirements in the model buy a BEV). Fuel cell vehicle do not enter the mass market due to the absence of a comprehensive hydrogen infrastructure in this scenario.

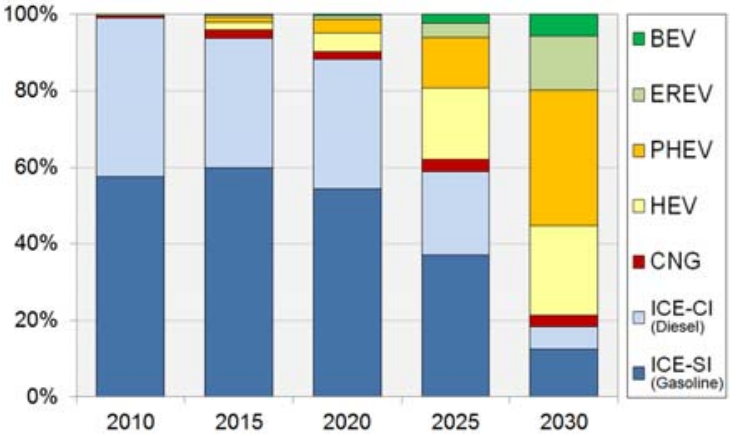

Figure 7: Market share of powertrain technologies in the German new vehicle fleet 2010-2030

\subsection{Impact on $\mathrm{CO}_{2}$ emissions}

According to the scenario simulation the $\mathrm{CO}_{2}$ emissions of the new vehicle fleet decrease by $47 \%$ until 2030 (see Figure 8). This decline is caused on the one hand by efficiency improvements of conventional cars through the introduction of new fuel save technologies (e.g. downsizing, start-stop generator, light weight design), on the other hand by the growing market penetration of electrified powertrain. The EU emission target of $70 \mathrm{~g} \mathrm{CO}_{2} / \mathrm{km}$ which is assumed for this scenario is exactly met in 2030 by the chosen technology mix. Also well-to-tank emissions of the new vehicle fleet can be reduced from 1.2 to 0.7 million tons $\mathrm{CO}_{2}$ per year in the time span 2010-2030 if the use of renewable energies in the electricity generation is expanded as planned by the German government [30].

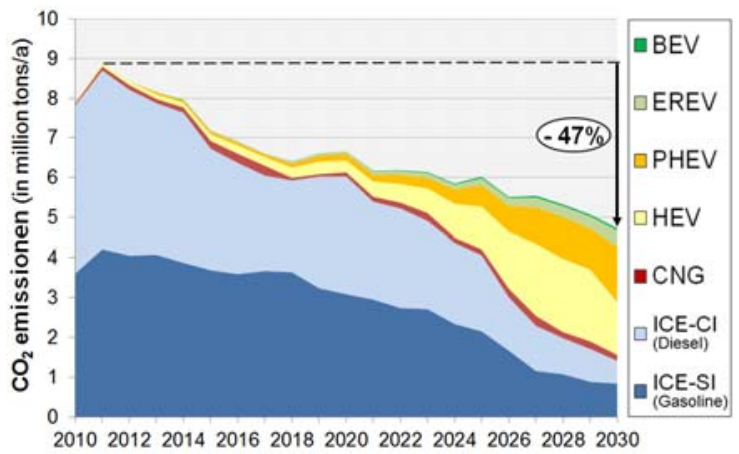

Figure 8: Development of annual well-to-wheel $\mathrm{CO}_{2}$ emissions of the new vehicle fleets by powertrain technology in Germany 2010-2030

\subsection{Impact on mobility costs}

However, the observed reduction of $\mathrm{CO}_{2}$ emissions and energy consumption does not come for free. The average investment costs for a buyer of a midsize passenger car will increase by EUR 3,900 
in the presented scenario. ${ }^{1}$ But at the same time the operating cost drop by about $20 \%$ despite rising energy prices. A detailed cost analysis of the scenario results shows that the improved energy efficiency of the advanced drivetrain technologies overcompensates the assumed energy prices increase, but does not fully offset the additional technology cost. So, over a period of 5 years the TCO for holders of medium size cars will be on average 5\% or EUR 1,700 higher in 2030 compared to 2010 (see Figure 9).

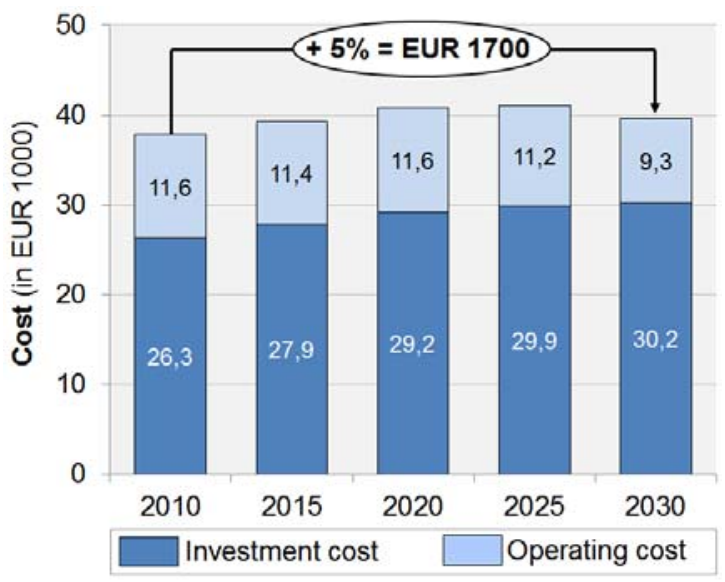

Figure 9: Development of average TCO for the holder of a midsize car over 5 years (in EUR 2010, excluding resale value)

\section{Conclusions}

In this paper an innovative utility based approach to model customer choice for alternative powertrains has been introduced which integrates the multi-criteria assessment of vehicle attributes and the diversity of user characteristics into a dynamic market scenario tool. The newly developed model could be successfully implemented and validated in a historic case study. Furthermore, the scenario model has been applied to analyse the prospective development of the new car market in Germany by 2030.

The simulation results show that under the assumed business-as-usual scenario the political target of 1 million electric cars by 2020 is likely to fail, if no additional effort is made. But in the time frame from 2020 to 2030 the number of alternative powertrains, especially advanced hybrid electric vehicles with grid connection

\footnotetext{
${ }^{1}$ In EUR 2010, excluding inflation and resale value
}

(PHEV, EREV), will grow significantly reaching a market share of $50 \%$. Nevertheless, none of the new propulsion concepts is expected to dominate the market within the next two decades. Therefore, OEMs have to adapt their R\&D strategies offering a broad portfolio of different powertrain technologies to meet customer demand while managing the increased complexity. Moreover, the market simulation demonstrates that a massive reduction of $\mathrm{CO}_{2}$ emissions in the new vehicle fleet by almost $50 \%$ in 2030 is possible through the improvement of existing technologies as well as the introduction of new efficient electric drivetrains. For the end customer this development will be associated with higher mobility cost compared to today's level.

In future studies the presented model should be applied to analyse the buying behaviour of different customer groups in more detail under varying scenario assumptions. The realistic modelling of user behaviour and preferences offers a great potential to gain additional insights such as the identification of potential early adopters and critical factors for the success of low emission vehicles.

\section{References}

[1] European Comission, White Paper on transport Roadmap to a Single European Transport AreaTowards a competitive and resource efficient transport system, Brussels 978-92-79-18270-9, 2011.

[2] BMVBS, Die Mobilitäts- und Kraftstoffstrategie der Bundesregierung (MKS), Berlin 2013.

[3] R. A. Daziano and E. Chiew, Electric vehicles rising from the dead: Data needs for forecasting consumer response toward sustainable energy sources in personal transportation, Energy Policy, vol. 51, pp. 876-894, 2012.

[4] T. E. Lipman and M. A. Delucchi, A retail and lifecycle cost analysis of hybrid electric vehicles, Transportation Research Part D: Transport and Environment, vol. 11, pp. 115-132, 2006.

[5] M. A. Delucchi and T. E. Lipman, An analysis of the retail and lifecycle cost of battery-powered electric vehicles, Transportation Research Part D: Transport and Environment, vol. 6, pp. 371-404, 2001.

[6] M. A. Kromer, A. Bandivadekar, and C. Evans, Long-term greenhouse gas emission and 
petroleum reduction goals: Evolutionary pathways for the light-duty vehicle sector, Energy, vol. 35, pp. 387-397, 2009

[7] O. van Vliet, T. Kruithof, W. Turkenburg, and A. Faaij, Techno-economic comparison of series hybrid, plug-in hybrid, fuel cell and regular cars, Journal of Power Sources, vol. 195 , pp. $6570-6585,2010$

[8] D. Santini, Y. Zhou, T. Stephens, V. Anant, N. Kim, and K. Gallagher, Cost Effective Annual Use and Charging Frequency for Four Different Plug-in Powertrains, SAE International, 2013

[9] S. Berry, J. Levinsohn, and A. Pakes, Automobile prices in market equilibrium, Journal of the Econometric Society, pp. 841890,1995

[10] K. E. Train and C. Winston, Vehicle choice behavior and the declining market share of us automakers, International Economic Review, vol. 48, pp. 1469-1496, 2007

[11] T. F. Golob, R. Kitamura, M. Bradley, and D. $\mathrm{S}$. Bunch, Predicting the market penetration of electric and clean-fuel vehicles, Science of the total environment, vol. 134, pp. 371-381, 1993

[12] A. Ziegler, Individual characteristics and stated preferences for alternative energy sources and propulsion technologies in vehicles: A discrete choice analysis for Germany, Transportation Research Part A: Policy and Practice, 2012

[13] D. Greene, Why the market for new passanger cars generally undervalues fuel economy, presented at the Joint Transport Research Center Round Table on Stimulating LowCabon Vehicle Technologies, Paris, 2010

[14] M. Redelbach, M. Klötzke, and F. Horst E. , Impact of lightweight design on energy consumption and cost effectiveness of alternative powertrain concepts, presented at the European Electric Vehicle Conference, Brussels, 2012

[15] DLR and infas, Mobilität in Deutschland (MiD) 2008, Bonn/Berlin 2010

[16] VerbraucherAnalyse. VA 2012 Klassik I Märkte http://www.verbraucheranalyse.de/auswertung/ online, accessed on 10-18-2012

P. Mock, Entwicklung eines Szenariomodells zur Simulation der zukünftigen Marktanteile und $\mathrm{CO}_{2}$-Emissionen von Kraftfahrzeugen (VECTOR21), Köln, 2010
[18] A. Kihm, S. Trommer, and M. Mehlin, Calculating potential emission reductions through the introduction of electric vehicles, presented at the Transporation Research Board (TRB), Washington D.C., 2013

[19] P. Plötz, T. Gnann, and M. Wietschel, Total Ownership Cost Projection for the German Electric Vehicle Market with Implications for its Future Power and Electricity Demand, in 7th Conference on Energy Economics and Technology Infrastructure for the Energy Transformation, 2012, p. 12

[20] D. Hülsebusch, J. Ungethüm, T. Braig, and H. Dittus, Multidisciplinary simulation of Vehicles, ATZ Worldwide Magazines, pp. 50-55, 2009

[21] ADAC, Autokosten 2010, Munich 2010

[22] KBA, Neuzulassungen von Kraftfahrzeugen und Kraftfahrzeuganhängern nach Herstellern und Handelsnamen Jahr 2010 (FZ4), Flensburg 2011

[23] P. Mock and S. A. Schmid, Fuel cells for automotive powertrains - A techno-economic assessment, Journal of Power Sources, vol. 190, pp. 133-140, 2009

[24] B. Propfe, M. Kroll, and H. E. Friedrich, Potential cost-degression of Lithium-ion batteries, presented at the Kraftwerk Batterie, Münster, 2012

[25] B. Propfe, M. Redelbach, D. J. Santini, and H. Friedrich, Cost analysis of Plug-in Hybrid Electric Vehicles including Maintenance \& Repair Costs and Resale Values, presented at the EVS26, International Battery, Hybrid and Fuel Cell Electric Vehicle Symposium, Los Angeles, USA, 2012

[26] M. Redelbach, B. Propfe, and H. E. Friedrich, Competitive Cost Analysis of Alternative Powertrain Technologies, presented at the IAMF 5, International Advanced Mobility Forum, Genf, 2012

[27] A. Dimitropoulos, P. Rietveld, and J. N. v. Ommeren, Consumer Valuation of Driving Range: A Meta-Analysis, 2011

[28] A. Rousseau, M. Redelbach, F. Le Berr, F. Badin, N. Kim, A. Da Costa, D. Santini, and H. Friedrich, Comparison of energy consumption and costs of different HEVs and PHEVs in European and American context, presented at the European Electric Vehicle Conference EEVC, Brussels, 2012

[29] IEA, World Energy Outlook 2011, 2011 
[30] BMU, Langfristszenarien und Strategien für den Ausbau der erneuerbaren Energien in Deutschland bei Berücksichtigung der Entwicklung in Europa und global, DLR, Fraunhofer IWES, IfnE2012

[31] European Parliament, Draft report on the proposal for a regulation of the European Parliament and of the Council amending Regulation (EC) No 443/2009 to define the modalities for reaching the 2020 target to reduce $\mathrm{CO}_{2}$ emissions from new passenger cars, 08.02.2013 2013

[32] IHS Global Insight, Light vehicle sales Europe by country and segment 2011-2020, 2012

[33] DIW, Verkehr in Zahlen 2011/2012 vol. 40. Auflage. Hamburg: Deutscher VerkehrsVerlag, 2011

\section{Authors}

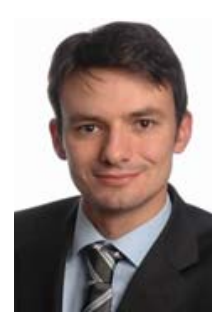

Martin Redelbach studied Mechanical Engineering and Business Administration at the Technical University of Darmstadt and the UC Berkeley. After working for McKinsey \& Company as a consultant he joined the DLR Institute of Vehicle Concepts in 2011. His research focuses on the assessment of alternative powertrains, customer choice and scenario modelling.

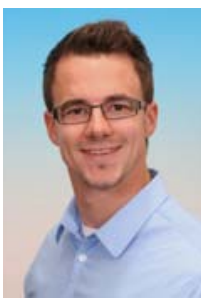

Michael Sparka is studying the master's degree program in Technology Management at the University of Stuttgart. Since 2012 he is working as research student at the DLR Institute of Vehicle Concepts in the field of Vehicle Systems and Technology Assessment.

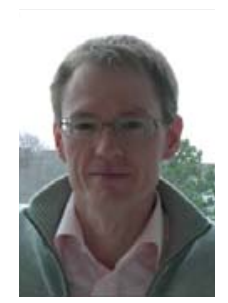

Stephan A. Schmid received a degree in mechanical engineering (Dipl.-Ing.) from the Technical University of Karlsruhe in 1996. He received a doctorate degree in engineering (Dr.-Ing.) from the University of Stuttgart in 2005. Since 2003 he is member of the scientific staff at DLR, where he is head of the department Innovative Vehicle Systems and Technology Assessment.

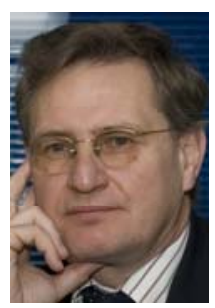

Prof. Dr. H. E. Friedrich is director of the Institute of Vehicle Concepts at the German Aerospace Center in Stuttgart and professor at the University of Stuttgart. The research fields are Alternative Power Trains and Energy Conversion as well as Light Weight Design and Hybrid Construction methods. 